\title{
O REFLEXO DA HISTÓRIA NA RECORDAÇÃO: RELAÇÕES ENTRE A HISTORICIDADE DE BUENOS AIRES DO SÉCULO XX E OS RELATOS DE MEMÓRIA DE NORAH LANGE
}

\author{
Nathalia Maynart Cadó* \\ Maria Eunice Moreira ${ }^{*}$
}

\begin{abstract}
RESUMO: O presente artigo busca relacionar aspectos presentes no livro Cadernos de infância de Norah Lange com o período histórico no qual foi escrito e que se encontra Buenos Aires no século XX. Será contextualizado que tal período foi muito importante para a nação argentina, pelo impulso modernizador da época, sociedade onde estava inserida Norah Lange e que, anos antes, presenciou e vivenciou quando criança. Percebe-se que, no livro, há fatores históricos implícitos, evidenciados e mostrados por meio deste trabalho.
\end{abstract}

Palavras-chave: Memória. História. Modernidade argentina. Infância. Norah Lange.

\section{Introdução}

As relações entre história e memória sempre sofreram a intersecção da verdade e nunca foram totalmente pacíficas. Segundo Beatriz Sarlo (2010, p. 9) "[...] nem sempre a história consegue acreditar na memória", ainda que sejam termos que caminham juntos ao largo da civilização. A história precisará de uma ou várias memórias para contar o seu testemunho, enquanto a memória necessita da história para que exista, bem como sujeitos que a compartilhem. A concepção de memória que é implícita aqui é a memória que está no sentido de recordar, implicando a subjetividade. Nas palavras de Aleida Assmann (2011, p. 33) ao diferenciar a memória no paradigma do armazenamento e da potencialidade, afirma que esta última provoca a recordação, ocasionando "[...] o patrono do paradigma da recordação formadora de identidade". Assim, será explicitado, juntamente com os elementos históricos presentes no romance, a importância na constituição do sujeito por meio da recordação de seus fatos e histórias, e como tais lembranças o constituem. No caso de Cadernos de infância, será visto a importância do relato pessoal como contribuinte do ser e seu contato com os processos históricos em que vivencia.

No presente artigo, serão discutidos os elementos memorialísticos presentes no romance Cadernos de infância, da escritora argentina Norah Lange em relação com o período histórico no qual este livro está inserido: um período de pós modernidade argentina e, ao mesmo tempo, uma antecipação de uma renovação na literatura nacional marcada por testemunhos do eu. Muitas vezes, se pensamos em um livro de marcos de infância, é difícil acreditar que nele se encontrarão relações com a historicidade da época. No entanto, segundo a autora Beatriz Sarlo, neste mesmo texto, há de se levar em consideração as condições de produção de uma obra em sua análise, condições temporais e culturais do texto para ter-se uma análise completa. Partindo desta afirmação e acreditando na relação em que a história sempre estará presente de uma forma ou outra na literatura, o presente texto irá relacionar elementos próprios da historicidade argentina da época em meio à história, num relato de uma

\footnotetext{
* Professora de língua espanhola na instituição básica e pesquisadora pela CAPES. Licenciada em Letras Português e Espanhol pela Universidade Federal do Rio Grande do Sul (UFRGS) e mestranda em Teoria da Literatura pela Pontifícia Universidade Católica do Rio Grande do Sul. (PUCRS).

E-mail: nathaliacado@gmail.com

** Professora titular da Escola de Humanidades - Letras da PUCRS. Graduada em Letras e em Ciências Jurídicas e Sociais. Especialista em Teoria Literária na PUCRS. Mestre em Linguística e Letras (Teoria Literária) pela PUCRS e Doutora em Linguística e Letras (Teoria Literária) pela PUCRS. Especialista em Língua e Literatura Espanhola pelo Instituto de Cooperación Iberoamericana. Pós-doutora pela Fundação Biblioteca Nacional de Lisboa com bolsa da CAPES. Membro do Centro de Literaturas de Expressão Portuguesa (CLEPUL) das Universidades de Lisboa.
}

IPOTESI, JUIZ DE FORA, v. 23, n. 2, p. 150-158, jul./dez. 2019 
narradora que relembra seus feitos de criança, e que nestes encontram-se muitos aspectos da modernidade da época. Primeiramente será, portanto, realizada uma contextualização das condições de produção da obra e, posteriormente, já na terceira seção, uma comparação entre a historicidade e o texto literário.

\section{As condições de produção: $o$ antes e o depois}

Antes de mais nada, o dado mais importante é a data na qual este livro foi escrito: 1937. Neste período, a Argentina recém provocara grandes mudanças em sua esfera social, o que afetou a configuração da sociedade e também da própria literatura. Ana Pizarro (2006), concordando com as palavras de Sarlo, diz que que a modernidade neste período é dada em dois planos: "Esta reflexão situa-se no espaço cultural concreto onde se encontram modernidade, enquanto concepção iluminista do desenvolvimento humano e social, e modernização tecnológica, uma das formas em que esta adquire, com maior força, seu vigor" (p. 60).

Durante as décadas de 1920 e 1930, período que antecede o livro e continuou até a década de 1940, a Argentina sofria, desde 1900, um forte período de imigração e presença estrangeira na capital Buenos Aires, o que resultou, artisticamente, nas palavras de Beatriz Sarlo (2010), em uma cultura de mezcla, onde a tradição e a modernidade estavam dialogando juntas em diversas esferas sociais. Segundo ela "Buenos Aires cresceu de uma forma espetacular nas duas primeiras décadas do século XX" (SARLO, 2010, p. 34) e, com isto, pode-se afirmar que o crescimento apenas continuou depois deste período. Norah Lange, ao vivenciar o que escreveu em Cadernos de Infância quando criança, viu uma cidade sendo transformada, o que depois, como aparece na citação abaixo, terá como aliado fundamental o passado biográfico que, no caso da escritora, posteriormente tornou-se no seu conjunto de relatos:

Creio que o impacto dessas transformações tem uma dimensão subjetiva que se manifesta num intervalo de tempo relativamente curto: de fato, homens e mulheres podem se lembrar de uma cidade diferente daquela em que estão vivenciando. Além disso, essa cidade diferente foi o cenário da infância ou adolescência: o passado biográfico destaca o que se perdeu (ou ganhou) no presente da cidade moderna (SARLO, 2010, p. 36).

Conforme Sarlo, portanto, será este o cenário em que a criança Norah Lange irá observar e que será o plano de fundo em que vivenciou os seus relatos. Posteriormente, ao escrevê-los, e concordando com o que foi dito pela teórica acima, a dimensão subjetiva igualmente estava ganhando espaço na Argentina e prolongou-se até a década de 1970. Beatriz Sarlo, na introdução de seu livro Tempo passado, comentará que as décadas de 1960 e 1970 na Argentina foi o auge dos relatos do eu, dos testemunhos em primeira pessoa: "Muito do que foi escrito sobre as décadas de 1960 e 1970 na Argentina (e também em outros países da América Latina), em especial as reconstituições baseadas em fontes testemunhais, pertencem a este estilo" (2010, p. 14).

Conforme Ana Pizarro (2008, p. 64) a separação entre o campo e a cidade também são consequências do processo modernizante, sofrendo mudanças no discurso, em que a voz do outro será importante neste período, bem como dar importância aos setores marginalizados, como os indígenas e as mulheres, e Norah Lange está inserida nesse contexto ao ser uma jovem escritora. Concordando com o que Beatriz Sarlo diz, neste mesmo período de modernidade, predominou uma dimensão cultural baseada no progresso e discurso individual:

IPOTESI, JUIZ DE FORA, v. 23, n. 2, p. 150-158, jul./dez. 2019 
O domínio da natureza - humana e social - vai adquirindo a certeza de seus espaços na vida cotidiana e na esfera pública, nos discursos de psicanálise e nos estudos da capital, como linhas que atravessam um discurso cultural que assenta suas utopias no progresso individual e coletivo (PIZARRO, 2008, p. 59).

Relacionando o fato de que a dimensão subjetiva proposta por Beatriz Sarlo anteriormente já existia em Buenos Aires nos anos de 1920-30 e perdurou até meados de 1970, pode-se concluir que esta dimensão também passou em meados da década de 30 e 40, época em que Norah Lange escreveu o seu livro. Tal dimensão subjetiva, em relação ao relato biográfico, significa a valorização do testemunho também como constituinte para contar ou recontar a história. Nas palavras de Beatriz Sarlo (2007), tal termo será conhecido como guinada subjetiva:

Restaurou-se a razão do sujeito, que foi, há décadas, mera "ideologia" ou "falsa consciência", isto é, discurso que encobria esse depósito escuro de impulsos ou mandatos que o sujeito necessariamente ignorava. Por conseguinte, a história oral e o testemunho restituíram a confiança nessa primeira pessoa que narra sua vida (privada, pública, afetiva, política) para conservar a lembrança ou para reparar uma identidade machucada (p. 19).

No entanto, segundo Sarlo, essa retomada do testemunho do sujeito criou relevância depois da década de 1960. Analisando o livro Cadernos de infância, percebe-se que o testemunho do eu, narrando sua vida então de forma afetiva, nota-se que há tal dimensão subjetiva em testemunhar sua memória, o que vê e o que sente, e isso já foi antecipado pela autora Norah Lange. Em resumo: o testemunho do eu não parece ter existido apenas depois de 1970, dando como exemplo de Cadernos de infância, que foi publicado em 1937 e que configura relações dentro da história com a sociedade argentina bonaerense da época.

A literatura, como já mencionado, também sofrerá suas mudanças, a ponto de estar a serviço do novo público leitor de Buenos Aires. Com cerca de $75 \%$ da capital tomada por imigrantes e presença estrangeira, a cidade também se moderniza com novas tecnologias, revolução nos transportes e na configuração em geral da cidade. A nova literatura de Buenos Aires será com a explosão de novas editoras voltadas para literatura de massa, como revistas e jornais. Neste mesmo período, as mulheres terão maior espaço na sociedade, trabalhando também nestes jornais e revistas - dado que será fundamental para posteriormente analisar no romance de Norah Lange -, sendo protagonistas também na publicidade, que se difundiu na época. A nova literatura, portanto, está ao acesso deste novo público leitor, ao mesmo tempo em que a modernização da cidade favoreceu com que as mulheres também frequentassem espaços públicos e ocupassem novos cargos de trabalho, além de tradicionais tarefas domésticas, como historicamente sempre foram preconceituosamente destinadas. A nova literatura, portanto:

Oferece um material montado sobre a base de artigos breves, que podem ser integralmente consumidos durante o trajeto para o trabalho, na plataforma do bonde ou nos vagões do trem e do metrô. O jornal, por seu formato de tabloide, não requer a comodidade da casa ou da escrivaninha (SARLO, 2007, p. 41).

Quanto à presença de mulheres na sociedade, Sarlo afirma que "os costumes sexuais se modernizam e as relações entre homens e mulheres se tornam mais liberais" ao mesmo tempo em que "[...] trabalham em ocupações não tradicionais [...]" (2007, p. 49) dando como exemplo não somente as mulheres que passaram a ser colunistas e trabalhar nas editoras, como também o lugar de Norah Lange nesta sociedade, de fundamental importância para entender o que essa autora vivenciava e era ao escrever Cadernos de infância.

IPOTESI, JUIZ DE FORA, v. 23, n. 2, p. 150-158, jul./dez. 2019 
Norah Lange nesta época era ainda uma adolescente -viveu entre 1906 e 1972 na Argentina, então, vivenciou todos os marcos históricos em questão -, mas tinha já grande importância no mundo intelectual. Teve contato ainda aos quinze anos com as estéticas em voga na época, o que "[...] lhe permitiu vincular-se desde cedo naturalmente com vanguardistas" (SARLO, 2007, p. 131), o que terá um reflexo significativo em sua obra, incluindo o romance em questão a ser estudado aqui:

\footnotetext{
Norah é um arco, mas é também uma mulher que conserva qualidades primárias básicas; pertence à formação da vanguarda, mas à resguarda das feiticeiras boêmias, que ainda incomodariam no Rio da Prata. É a literatura e o lar [...] as estritas normas morais que regem a casa da Calle Tronador, onde sempre se conservou a "balança dos nascimentos", em que a mãe Lange pesava suas filhas conforme iam chegando ao mundo (SARLO, 2007, p. 133).
}

Além de estar por dentro das vanguardas e ter grande conhecimento dos textos do ultraísmo portenho, Norah irá refletir em sua escritura, tanto em romances quanto em poesias, a forte contensão familiar e os cuidados da mãe, conforme citação acima mostra igualmente. O contato com as vanguardas e Norah Lange, tendo como exemplo o ultraísmo, refletem-se com o período imigratório da época. Segundo Ana Pizarro, com a explosão dos novos setores imigrantes, chegam também às grandes urbes do sul as correntes ideológicas que circulavam na Europa. Tais correntes são tanto reivindicações populares quanto pode-se dizer também que as vanguardas estéticas, fora que Norah Lange já tinha um conhecimento muito grande do ultraísmo argentino. Para Ana Pizzarro, as vanguardas na América Latina em geral, e assim incluindo Buenos Aires:

Trata-se de uma ruptura como processo do discurso e, nela, a cidade com seu urbanismo desenfreado, cosmopolita, sonho de modernidade se inscreve como linguagem poética privilegiada, em múltiplas estratégias: propostas simultaneístas, rupturas cronológicas, descrição analítica cubista, a fragmentação que reorganiza a linguagem, buscando diferentes virtualidades de expressão tempo-espaciais, para dar conta desta relação nova do sujeito com o meio urbano (2006, p. 67).

O discurso literário, desta forma, sofreu modificações em função das vanguardas, encontrando modelos alternativos, ou seja, o discurso literário estava se modificando de acordo com o processo de modernização que sofria Buenos Aires, e isto foi graças também às vanguardas, onde Norah Lange estava inserida. Por fim, confirma-se que pela primeira vez na América Latina a urbanização das cidades superava em número de habitantes quem habitava a região do campo, bem como separou a cidade do campo, oriundo das transformações tecnológicas, deixando Buenos Aires com um caráter europeu. Tais transformações urbanas refletiram na literatura e em seu discurso, na arte, na cultura e na forma de pensamento das pessoas, mostrando que a modernidade em Buenos Aires foi além de mudanças no setor tecnológico, e que a verdadeira modernização está na ideologia e forma de enxergar o mundo.

\section{Cadernos de infância: uma análise crítica no momento do relato e no da escrita}

Em Cadernos de infância, conforme se vê pelo título, selecionou fatos de sua adolescência e infância para relatar as memórias de sua vida, mais especificamente dos cinco aos 14 anos. O relato no livro está em primeira pessoa e, como o título sugere com a palavra cadernos, cada capítulo, curto em extensão, é uma memória, um acontecimento de sua infância que lhe marcou. Cada capítulo é interdependente entre si, seguindo certa cronologia de acordo com os anos de sua idade, mas as estruturas e os episódios não possuem relação entre um capítulo e outro. Utilizando Aleida Assmann (2011) pode-se dizer que se trata de um

IPOTESI, JUIZ DE FORA, v. 23, n. 2, p. 150-158, jul./dez. 2019 
livro de recordações, pois, segundo ela, a memória cultural depende de um conhecimento partilhado, de mídias e políticas, enquanto a recordação está registrada como processos que ocorrem "[...] espontaneamente no indivíduo e seguem regras gerais dos mecanismos psíquicos" (p. 19). Além disso, outro fato importante, segundo a autora, é que nas recordações há o processo de construção de identidade do sujeito (ASSMANN, 2011, p. 23), logo, pode-se dizer que Cadernos de infância busca pontuar subjetivamente e historicamente o lugar da autora na literatura argentina. É um relato feito em primeira pessoa, como já dito, porém não mais em sua perspectiva como criança, mas já como uma autora madura recordando, conforme Aleida Assmann, dentro do tempo, na perspectiva em que acontecem, mergulhando em seu passado quando criança. Em relação ao processo de identidade, pode-se dizer que tais relatos provocam transformação na recordação quando ela é recuperada novamente, que é o momento da escrita do romance:

A recordação procede basicamente de forma reconstrutiva: sempre começa do presente e avança inevitavelmente para um deslocamento, uma deformação, uma distorção, uma revaloração e uma renovação do que foi lembrado até o momento de sua recuperação. Assim, neste intervalo de latência, a lembrança não está guardada em um repertório seguro, e sim sujeita a um processo de transformação (ASSMANN, 2011, p. 34).

Além disso, tal recordação, quando é lembrada novamente, também implica na constituição de sua identidade e também está presente no relato de Norah Lange, pois a autora quando criança vai se modificando ao decorrer do tempo. Indo para uma perspectiva de recordação mais histórica, a palavra cadernos, pensando no momento histórico de Buenos Aires, na difusão grande de editoras de jornais, revistas e literatura para ser lida no transporte público, no intervalo do trabalho, enfim, sem necessitar o conforto da residência de seus leitores, o título pode remeter-se, portanto, a um livro que pode ser lido em distintos lugares sem necessitar de grandes luxos, sem contar os seus capítulos independentes que deixam claro que é um livro que pode ser lido num período curto ou grande de tempo, podendo lê-lo em meio a outras leituras também. Assim, interpreta-se que a palavra cadernos foi intencionalmente posta em relação ao tipo de literatura consumida na época.

O prefácio da presente edição de Cadernos de infância, escrito por Julian Fuks resumiu a situação da família que parece estar, ao longo da narrativa, num processo contínuo de momento: "Cadernos de infância conta a história de uma família numerosa que vai de Buenos Aires a Mendonza, e de Mendonza a Buenos Aires [...]" (2009, p.11). Desta forma, pode-se relacionar a situação da família de Norah Lange com o período histórico e social de imigração em Buenos Aires que começou depois de 1900. Claro, a família de Norah não era estrangeira, mas pode ser comparada esta situação de mudanças ao fato de que muitas pessoas saíram do campo e de outras cidades para migrarem até a capital na época.

O terceiro ponto importante a ser ressaltado em relação à sua historicidade é o fato de que suas memórias de infância são construídas com base em suas percepções, acontecimentos e recordações com suas irmãs e a mãe. As irmãs se chamam no relato Irene, Marta, Georgina, Susana e Esthercita, a bebê que faleceu aos quatro anos. A mãe, embora não pareça ter muita afinidade com Norah Lange, sempre aparece como heroína, em forma de admiração. Percebese na história, portanto, que há uma construção e valorização da figura feminina, uma visão de feminilidade que vai se desenvolvendo ao longo da narrativa e também em relação ao quanto cresce e amadurece:

No decorrer desse inverno sofreu apenas três desmaios. Para fortifica-la, obrigavamna a alimentar-se muito e a fazer exercício, montar a cavalo. Nada me parecia tão absurdo como isso de lhe imporem um regime para despojá-la da anemia que a

IPOTESI, JUIZ DE FORA, v. 23, n. 2, p. 150-158, jul./dez. 2019 
afligia, e, sempre que ela resistia a um segundo copo de leite, a uma torrada, eu recuperava neste fastio a certeza de sua feminilidade (LANGE, 2009, p. 61).

A visão de Norah Lange sobre a figura feminina na época ainda parece ser um pouco conservadora, patriarcal e até rotulada sobre a mulher: sujeito frágil, que desmaia, delicada: "Nesta época eu estava convencida de que as mulheres devem ser muito débeis, fisicamente, e que uma espécie de languidez, uma perpétua convalescença constituía a característica de sua verdadeira feminilidade" (2009, p. 60).

Tal visão pode estar relacionada com o conceito de mulher que era empregado na época e pode-se dizer que estava numa espécie de transição. No livro de Ana Pizarro, há o indício comentado de que, na época entre 1920-30, ou seja, período pouco posterior da vivência infantil de Norah Lange, Buenos Aires estava em um período de novas correntes ideológicas e manifestações populares em que "Trata-se de grupos que circulam em torno do café, da imprensa, das associações, jornais e movimentos feministas" (2006, p. 62) e, ao mesmo tempo, o período em que Norah Lange tem tal concepção feminina, muitas mulheres estavam começando a inserir-se na sociedade e trabalhando em cargos que antes eram ocupados apenas por presenças masculinas. Tem-se como exemplo o próprio caso de Norah Lange, que em sua época trabalhava na revista Martín Fierro, conforme citação abaixo: "Era a animada anfitriã dos principais encontros literários bonarenses, a jovem que subia em caixotes para professar discursos graciosos, verborrágicos, engraçados, a solitária assinatura feminina no expediente de Martín Fierro, Proa e outras revistas de vanguarda" (LANGE, 2009, p. 8).

Ou seja, o feminismo nesta época, ainda que de forma implícita, nota-se que ele estava inserido em manifestações populares, cargos laborais, publicidade e, consequentemente, na literatura, em ter protagonistas, personagens e escritoras fortes. No caso do romance Cadernos de infância, conforme trechos já mencionados, percebe-se que eis uma narrativa construída em torno de suas vivências com a mãe e suas irmãs - este é o principal cenário da obra - e por este motivo nota-se que ao utilizar o pronome pessoal "nós" em vários momentos está incluindo ela e suas próprias irmãs: "Nós cinco, vestidas de blusa marinheira branca, aguardávamos com tal impaciência que nos parecia que mamãe demorava muito para se arrumar, que a ama-seca tardava mais do que outras vezes em colocar Eduardito para dormir" (LANGE, 2009, p. 13).

Além disso, ao longo desta narrativa, as figuras masculinas como o pai e Eduardito nunca são incluídas no pronome pessoal nós, ou seja, desta forma nota-se que há esta concepção sobre o ser mulher que vai construindo, da mesma forma que Buenos Aires estava configurando e relevando cada vez mais a figura feminina, como se Cadernos de infância e o fato histórico caminhassem simultaneamente quanto ao estabelecimento do lugar da mulher na sociedade.

Há um próximo fator que se relaciona com a historicidade da época que é a característica que tinha por si quando criança em ser uma jovem bastante observadora. $\mathrm{O}$ ato de observar era bastante presente, segundo suas memórias, principalmente ao dizer que tinha o costume de "introduzir-se" na pessoa ao notá-la:

Desde bem pequena eu gostava de observar os outros com muita atenção. Aos 6 anos, esse já era um costume bastante arraigado em mim. Depois eu ria; ria tanto que mamãe tinha de avisar às visitas que eu era muito "cheeky" [...] esse hábito me acompanhou até que fiquei mais velha e pude analisa-lo. Ao cravar os olhos nas pessoas que vinham nos ver - o pároco, o médico da vila, o bispo de $\mathrm{X}$, todos os visitantes que deviam ser hóspedes de nossa casa - eu imaginava o seu perfil por dentro. Era como se me introduzisse na pessoa, fisicamente, mas só no rosto (LANGE, 2009, p. 28)

IPOTESI, JUIZ DE FORA, v. 23, n. 2, p. 150-158, jul./dez. 2019 
A figura de sujeito observador, neste período em que Norah Lange vive o seu relato será conhecido como flâneur e, assim como a autora, também tem essa característica de observar as pessoas e o seu entorno. Um flâneur, na visão de Beatriz Sarlo, é um sujeito que anda de forma anônima e desconhecida pela grande cidade, lançando "[...] o olhar anônimo daquele que não será reconhecido por aqueles que são observados [...]" (SARLO, 2010, p. 34) podendo ser comparado, desta forma, à característica de Norah Lange em ser bastante observadora não somente quando criança, mas também, conforme seu relato, em sua forma adulta. Tal caráter observador até a fase adulta dá como consequência o seu aprecio pelas estéticas vanguardistas que, como já explicado anteriormente, entram em Buenos Aires com o impulso modernizante da época, ocasionado pela grande presença estrangeira, e alteram o discurso cultural em muitos escritores modernos da época, a exemplo de Norah Lange. Uma das características presentes tanto no livro quanto na sua perspectiva observadora é que sua narração em superioridade mostra o fato do que os explica, podendo relacionar com a característica da vanguarda em mostrar o que está além de seu tempo, em um de seus conceitos clássicos. No livro Cadernos de Infância há a presença tanto de fatos quanto de imagens construídas pela narradora (mostrando e não explicando ou aprofundando) que estão fazendo uma ponte, ligação com o movimento vanguardista da época. Um exemplo é a sua brincadeira de infância e recortar palavras, podendo ser relacionada a movimentos estéticos vanguardistas como o dadaísmo:

“[...] eu me distraía, sentada no chão, com meu passatempo favorito. Com uma tesoura, recortava as palavras dos jornais locais e estrangeiros e ia empilhando-as em montinhos. Na maioria das vezes, desconhecia-lhes o significado, mas isso não me preocupava nem um pouco. Só me atraía o aspecto tipográfico, a parte densa ou rala das letras" (LANGE, 2009, p. 39)

Tal passatempo, neste relato, foi supervisionado sob a babá e também que lhes ensinava, que era a senhora Miss Witheside, mulher estrangeira e que provavelmente participou do processo de imigração de Buenos Aires que vinha desde 1900. Não apenas de recortar palavras, mas outro tópico vanguardista que aparece é a invenção de palavras, também podendo estar relacionado ao movimento dadaísta e sua desconstrução, dando como por exemplo a palavra Itilínkili: "[...] umas cócegas me levantavam o dedo anular, separandoo dos outros, e que essas cócegas se traduziam em uma palavra: "Itilínkili". (LANGE, 2009, p. 54). Por fim, a imagem do cavalo pode também estar relacionada ao movimento de vanguarda podendo relacionar-se com o movimento surrealista, por exemplo, na cena em que ele vai afundando, ou a imagem do menino que ficava dentro de um caixote, no início do romance. No trecho abaixo, em um dos mais emblemáticos que é a morte do cavalo, a autora tenta implicar um sentimento ao animal e esta ser a sua crença:

Ouviu-se um relincho entrecortado, dilacerante, e, quando o cocheiro correu para ele, encontrou-o fora do potreiro, uma pata enganchada no alambrado [....] $\mathrm{Na}$ manhã seguinte, muito cedo, quando meu pai se dirigiu à cavalairiça, seu tordilho já havia morrido. Morreu de ciúme. Assim o compreendi e assim quero continuar acreditando sempre (LANGE, 2009, p. 86-87).

Estes e diversos outros fatos históricos podem ser encontrados implicitamente no livro e, desta forma, relacionando recordação não apenas como imagem subjetiva e constitutiva de identidade, mas também que esta é constituída pelos elementos históricos que a circulam.

\section{Conclusão}

IPOTESI, JUIZ DE FORA, v. 23, n. 2, p. 150-158, jul./dez. 2019 
Neste artigo foi mostrado, primeiramente, a contextualização histórica do momento tanto em que Norah Lange vivenciou quando criança quanto as condições de produção de seu livro, comparando historicidade e o texto literário, tomando como base a importância das condições de produção de um texto para que ele circule socialmente e também a relação entre recordação e história como constituintes do sujeito. Na primeira parte, houve a discussão sobre o movimento modernizante de Buenos Aires do século XX dado graças ao processo de imigração, em uma modernização social e tecnológica. Neste contexto e de tantas inovações, o surgimento de um passado biográfico e uma guinada subjetiva baseada nos discursos do eu, relatando o que se perdeu e o que se ganhou com tantas mudanças sociais e culturais. Tais câmbios provocaram alterações também no discurso literário, em que este deu voz aos marginalizados, como a voz das mulheres. O movimento de vanguarda também foi crucial para a consolidação deste processo.

$\mathrm{Na}$ segunda parte, foram analisados elementos em relação à modernidade, dando como exemplo a palavra cadernos e sua relação com a nova literatura produzida na época, a criação de um livro de recordações que tinha como plano de fundo a constituição de um sujeito feminino. Ainda, de forma próxima com o vanguardismo de Norah Lange, o ato de recortar e criar palavras. Estas e outras relações - mencionadas aqui ou não - afirmam os laços presentes entre literatura e história, e como as mudanças destas se refletem na ficção e alteram os discursos.

\title{
THE ECHO OF HISTORY ON RECOLLECTION: THE RELATIONSHIP BETWEEN HISTORICITY OF $20^{\text {TH }}$ CENTURY BUENOS AIRES AND NORAH LANGE'S MEMORY ACCOUNTS
}

\begin{abstract}
This study aims to establish a relation between the features present in the book Cadernos de Infância by Norah Lange and the historical period in which it was written and that Buenos Aires was in $20^{\text {th }}$ century. That period will be contextualized as it was very important for Argentinean nation due to modernizing impulse of the time, a society in which Norah Lange took part and some years before she lived and witnessed as a child. One can notice that in the book there are implicit historical facts which will be highlighted and shown throughout this study.
\end{abstract}

Keywords: Memory. History. Argentinean Modernity. Childhood. Norah Lange.

\section{Referências}

ASSMAN, A. Espaços de recordação: formas e transformações da memória cultural. Tradução Paulo Soethe. Campinas: Unicamp, 2011.

LANGE, N. Cadernos de infância: memórias. Tradução Joana Angélica D`Avila Melo. Rio de Janeiro: Record, 2009.

PIZZARRO, A. O sul e os trópicos: ensaios de cultura latino-americana. Tradução Irene Kallina e Liege Rinaldi. Niterói: UFF, 2006.

SARLO, B. Tempo passado: cultura da memória e guinada subjetiva. São Paulo: Companhia das Letras; Belo Horizonte: UFMG, 2007, p. 9-44.

IPOTESI, JUIZ DE FORA, v. 23, n. 2, p. 150-158, jul./dez. 2019 
SARLO, B. Modernidade periférica: Buenos Aires 1920 e 1930. Tradução Júlio Pimentel Pinto. São Paulo: Cosac Naify, 2010.

Data de submissão: 22/06/2019.

Data de aceite: 01/09/2019. 